\title{
Mass Timber Design Research at the Nexus of Practice and the Academy
}

Mass timber's composition and manufacturing processes enable masscustomizable building assemblies for performance-based design. In addition to architectonic appeal, mass timber construction offers an array of societal benefits ranging from 1) improving forest management and health, 2) increasing rural economic development, and 3) providing a locally sourced, low-carbon construction material.

TODD BEYREUTHER

Washington State University

\section{DARRIN GRIECHEN}

Washington State University

\section{INTRODUCTION}

Mass timber is an emergent building assembly technology that advances themes of prefabrication, modularization, parametric design, and renewable materials in architectural practice and education. Mass timber is a collective term for several engineered heavy panel wood products including cross-laminated timber (CLT), nail-laminated timber (NLT), glued laminated timber (GLT) laminated veneer lumber (LVL), laminated strand lumber (LSL), and parallel strand lumber (PSL). Mass timber's composition and manufacturing processes enable mass-customizable building assemblies for performance-based design. In addition to architectonic appeal, mass timber construction offers an array of societal benefits ranging from 1) improving forest management and health, 2) increasing rural economic development, and 3) providing a locally sourced, low-carbon construction material. Washington State University (WSU), as the land-grant institution for the State of Washington, has taken a lead role in the research, development, and adoption of this emerging technology in the Pacific Northwest. This paper explores mass timber methods utilized and knowledge generated from two design research activities related to teaching at the Academy and application with Practice.

The WSU Institute for Sustainable Design (ISD) - a collaboration between two design and engineering teaching units and one material science and engineering research unit in the WSU Voiland College of Engineering and Architecture - has developed two synchronous design 'vehicles' to drive innovation with mass timber efforts: a studio course called the Integrated Design Experience (IDX) to conduct teaching activities and the Integrated Design Lab (IDL) to conduct research and outreach activities. IDX and IDL connect design thinking models of studio instruction in architecture with funded research and stakeholder outreach projects in engineering and the sciences at WSU. Allied sponsored research projects have included the design of pilot supply chains for biofuels and coproducts from forest residuals (USDA-NIFA Competitive Grant no. 2011-68005-30416, \$40M awarded, IDX 2010-2016), mass-customization of hybrid CLT panels (USDA-NIFA Competitive Grant no. 2013-05984, \$264k awarded, IDX 2014-2015), design and engineering of tall wood buildings (USDA 
Tall Wood Competition, finalist, \$2.4M proposed, IDX 2014-2015), and CLT manufacturing and supply chain technomarket analysis in the Pacific Northwest (USDA-FS-WERC 2015 Competitive Grant, \$250k awarded + \$394k cost share with partners, IDX 2015-2017). The two integrated design vehicles (IDX + IDL) bridge gaps between Practice and the Academy while enabling an appropriate level of creative autonomy necessary to drive innovation in complex, wicked problems such as the development and adoption of mass timber systems.

\section{SCHOLARSHIP OF DISCOVERY}

Like all mature institutions, Practice and the Academy share inherent resistance to change. Traditions are valued, tested, and slow to evolve. Yet, both institutions take pride in innovation; in the ability to not only discover new knowledge, but to do it with unique methodologies. French philosophers Gilles Deleuze and Félix Guattari differentiated between the slow 'striated space' of institutionalized apparatuses and the fast 'smooth space' of the in-between (Deleuze and Guattari, 1987). They argued that inhabitants of smooth space are 'nomads' that innovate to disrupt institutional apparatuses. For individuals, ideas and initiatives that inhabit existing institutional striations opportunities to innovate are limited without extraordinary measures or energy. When these excited states happen, ideas deterritorialize and become 'nomads' within smooth space allowing innovation to develop. Eventually, these innovations are incorporated into the bounds of institutional striations and define new norms. As both Academia and Practice take on the wicked problems of our age, it becomes imperative to find ways to innovate (Brown and Harris, 2010).

Designers solve 'wicked problems' - problems where both the solution and the path towards and solution are unknown (Buchanan, 1992). Designers rely on and are comfortable with iterative processes of ideation and application to accomplish this. For architects, these processes are hard wired from academic studio training and lead to innovation and discovery on projects. However, hard wiring this process in actual institutional structures remains challenging.

This paper proposes that the integrated design vehicles of IDX and IDL at Washington State University enable these nomadic challenges and opportunities between the striations of academic-based teaching apparatuses and practice-based application apparatuses (Figure 1).

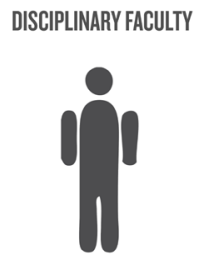

TEACHING

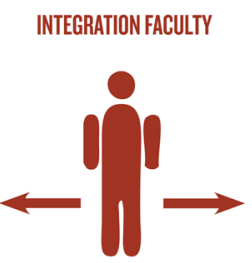

DISCOVERY
PRACTITIONERS

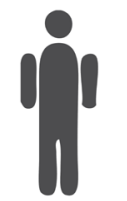

APPLICATION 1

\section{SCHOLARSHIPS OF TEACHING AND APPLICATION}

The Academy and Practice exist within a spectrum between teaching and application. Professional practitioners of architecture typically emphasize application while schools typically emphasize teaching due to the inherent contexts each exist in. Each seeks their own appropriate balance between teaching and application. Formal mechanisms to achieve this balance are necessary when rutted in deep institutional striations. Architects in Academia and Practice exercise many mechanisms to momentarily break out of these striations (to deterritorialize per Deleuze). These moments offer important freedom or divergence from the rigid task at hand to facilitate creative leaps and contemplation - core elements in design thinking and ideation (Cross, 2006). Examples of these mechanisms include 
charrettes, competitions, and scholarly design activities of writing, drawing, and modeling. These divergent activities are uniquely bi-directional equally pulling academics towards application and practitioners towards teaching - blurring ownership of either scholarly activity to the Academy or Practice. Methods in IDL and IDX attempt to not only utilize these mechanisms, but to also teach the underlying design theory.

\section{TEACHING METHODS: IDX}

The Integrated Design Experience (IDX) is envisioned as a studio-based teaching mechanism between siloed disciplines within Washington State University seeking solutions for grand built and natural environment challenges (Figure 2). Projects within IDX have ranged from the ideation and design of a data-driven organic farm, building and infrastructure design for Washington State ferry terminals, building and industrial site design for a regional biofuels supply chain, and most recently building and assembly design for mass timber supply chains, the topic of this paper. Projects undertaken in IDX share certain common features. First, the complexity of the problem requires interventions at a range of scales from the region down to the human. Second, the problems touch several disciplines which require collaboration in order to innovate. Finally, the problems have near-term practical applications. This last feature is a significant factor in the ability to reach out to industry and professional partners for interest and support. This outreach also addresses the land grant mission of Washington State University.

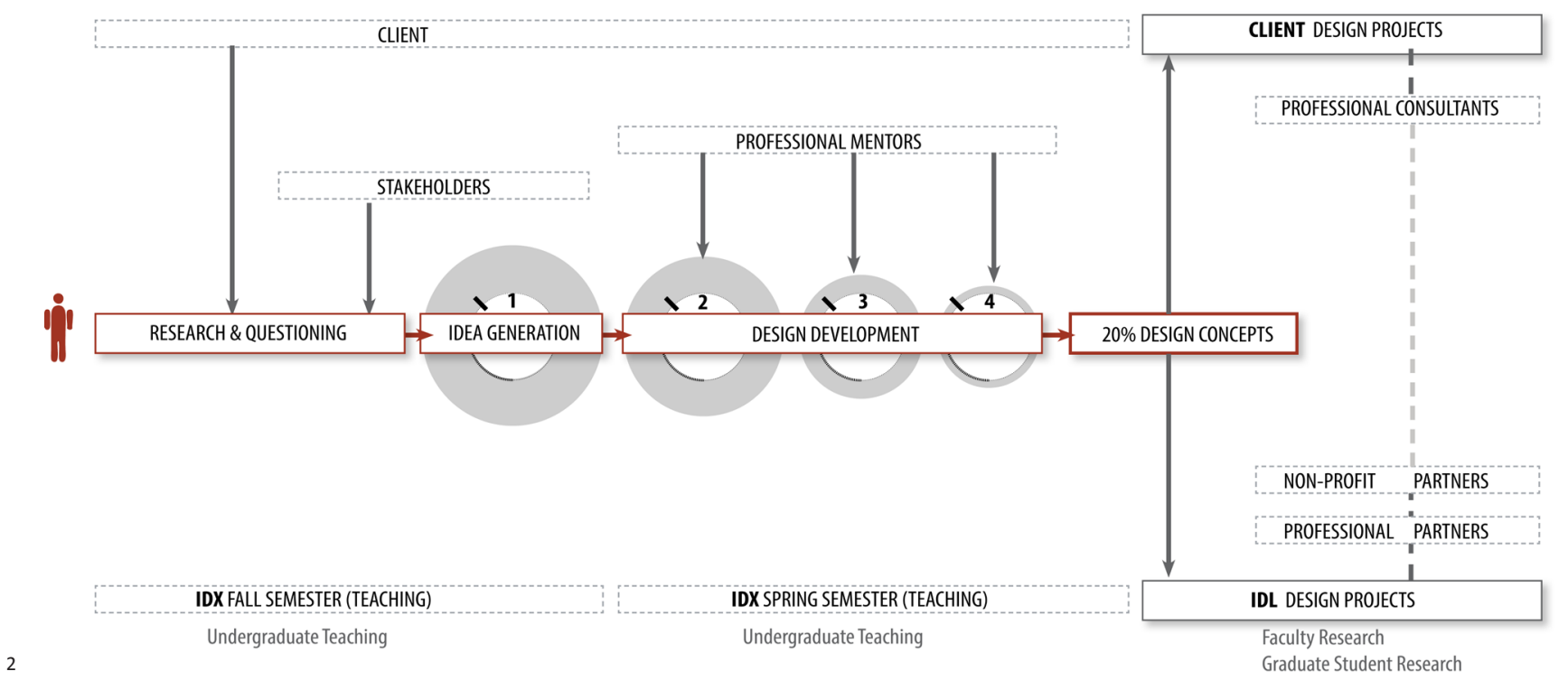

Figure 2: Integrated Design Model

IDX courses generally consist of a core college-wide elective course and allied departmental courses. At times the research being conducted in the core course does not directly align with the curricular needs of a given discipline participating. In these situations, the allied courses are spun off to allow for focused teaching that fulfills curricular needs yet address themes related to the research problem. The outcomes of these allied courses may not directly address the fiduciary responsibilities of the sponsored research, yet they provide valuable perspectives and engagement by students and faculty for the current project and for future research development.

A key component in the IDX model is the integration of professional mentors into the studio experience. These mentors are engaged early in the studio as the project is introduced and then at strategic points during the semester for student feedback. These engagements take 
place face-to-face and via videoconference. The practical perspective of the professional mentors tempers the trajectory or student ideas while at the same time the mentors are exposed to new ideas, thus altering their perspectives as well. The end product for the studio is envisioned as a fully formed innovative idea that shows promise for application and is ready for handoff to professional partners for further development (Figure 3).

The premise of the core IDX course is to provide the students the skills, infrastructure, and setting to apply design thinking methods in order to develop innovative insights and solutions with respect to the research topic. The course is modeled on the design studio model. For most non-design students, design thinking and the studio mentorship model are new approaches to problem solving.

The design thinking method and the design studio model ask participants to engage in a nonlinear iterative process where the outcome is an emergent condition. The (often) unpredictability and range of outcomes are the method and model's strength in this setting. Often, students outside the design disciplines find it unsettling that there is not a clearly defined checklist or formula to be applied to arrive at a singular solution. A good deal of care and mentoring are needed to get them to the point in which they are confident enough to really explore possibilities. The inherent one-on-one interaction between student and instructor of the studio model is ideal to overcome this initial hurdle. Having design students collaborate also eases the transition significantly because they are familiar with the design studio model and design thinking methodology.

In addition to learning design thinking, students are exposed to project infrastructure consisting of a rigorously organized asset management protocol, graphic standards, and numerous software/hardware assets. A series of workshops are used to introduce the students to the knowledge and skills required for research methods, documentation skills, diagramming, GIS, graphic design, and parametric design among others. Students learn several new software applications. For many it can be daunting at the beginning, but they quickly help each other get up to speed.

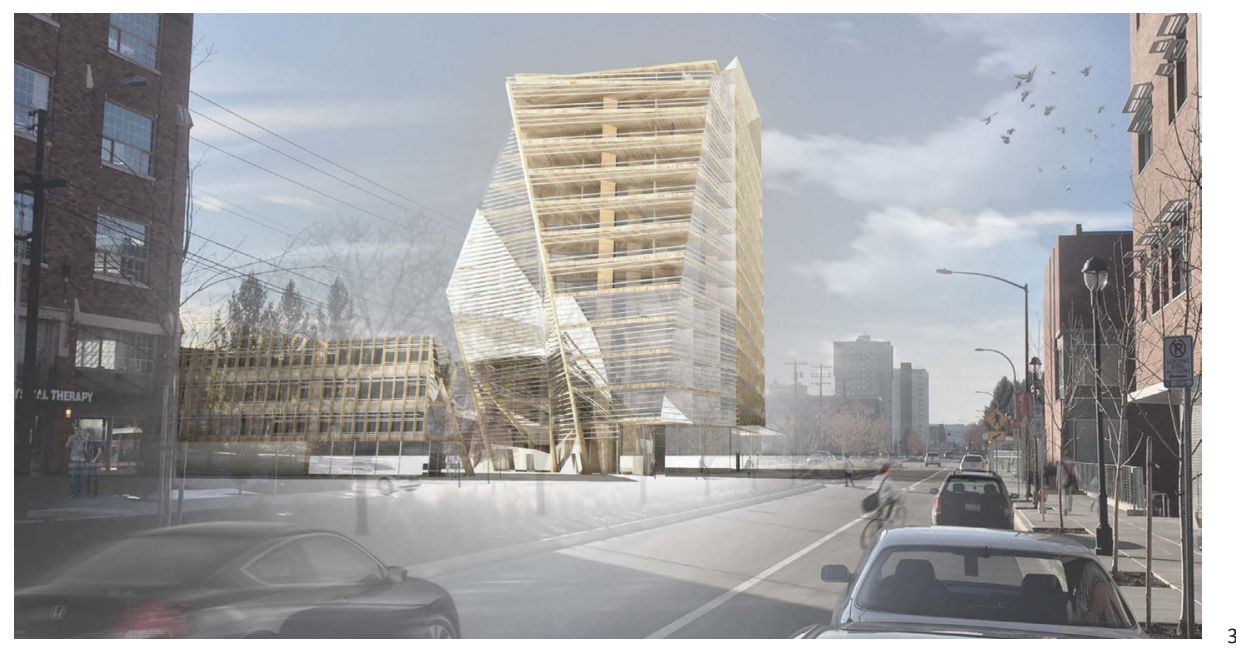

The IDX course/studios begin by introducing the students to the context and scope of the research topic by experts from both academia and professional spheres while simultaneously learning software and design thinking methodologies. This is followed by a group research phase with the goal of each group being able to provide peer expertise in a specific topic throughout the course of the studio and to produce base assets such as diagrams, bibliographies, and inventories which will be used throughout the semester. The students then engage in brainstorming and charrette exercises to identify early innovation trajectories
Figure 3: IDX Student Work, Brian Dorsey 
for further exploration. Another round of research related to the trajectories is undertaken before the groups begin developing their innovations further.

The 2014-2015 IDX Mass Timber studio paralleled the development of a WSU entry to the USDA Tall Wood Competition with professional architecture, engineering, construction, and building operations (AECO) partners including Miller|Hull (architecture), Arup (structural and fire engineering), Berg (manufacturing), McKinstry (mechanical and electrical engineering), and Sellen (construction). The students engaged the same site and programmatic criteria as the professional team. Because of confidentiality agreements with the competition sponsors, the team could not share specific results with the students. However, Miller|Hull architects participated in design reviews of student work. As the Principal Investigator was also an instructor for the course, information was exchanged in terms of analysis, programming, and structural strategies.

A conceptual design framework was developed that was easy to understand and implement with computational design tools used in the course. The framework provided students methods to break down the design problem into discrete parts and to oscillate between general and specific concerns while iterating through design solutions. The framework consisted of three categories: Intent; Method, Outcome. Students began by capturing their design intent by elaborating a set of principles, general statements of performative intent with multiple possible solutions, and rules, specific prescriptive objectives with singular solutions. This was followed by methodically interpreting the previous statements of intent into systems of parameters. Students were encouraged to engage in the difficult (perhaps impossible) translation of qualitative properties into quantifiable systems while also researching real world ranges and data for quantifiably direct parameters. The completed parametric system formed the 'genes' of the team's building, its 'genotype'. By varying the inputs of the parameters individual instances of the building, 'phenotypes', were generated. This method allowed students to explore significant numbers of design permutations and also to implement evolutionary solvers to cull permutations for specific design criteria.

Student computational design and tool knowledge levels varied significantly. To overcome this, students were taught basic computational thinking without using any tools. To create a solid foundation emphasis was put on breaking down problems into discrete parts (functions) that were defined and elaborated as 'pseudocode', just basic english sentences describing the process step by step. This allowed the students to focus on their intent in focused ways and without worrying about implementing them with the computational design tools they were unfamiliar with. Later they used these to implement them computationally.

Integrated student teams (architecture, structural engineering) used the above framework and computational design tools and methods to perform site and program analysis in parallel to the professional team. The students collaboratively developed baseline 'genotype' parametric building models that responded to site, climate, program, and structural patterning in pre-design. Engineering students developed parametric analysis tools for evaluation of iterative structural decisions. Architecture students further developed conceptual designs representing multiple phenotypic models that emerge from the collaborative genotype programming.

The development of the group genotypes in the fall semester allowed the students to quickly develop their own individual projects (phenotypes) within a short time span and to achieve a level of detail that enabled them to transfer their parametric models into Revit for development of technical drawings. The workflow between Rhino/Grasshopper and Revit was an area that took significant technical investigation to find the the appropriate set of tools and set appropriate expectation levels for the technology as it stands at the moment. 
Undertaking these activities uncovers the need for new tools, but also contributes to the development and refinement of existing tools and workflows. Collaboration with practitioners is important in order to hone these tools and techniques for application in real world scenarios and workflows. The computational methods and tools used in this studio to analyze and explore design possibilities have not become the norm in architectural practice, but their holistic integration by SHoP Architects and exploration by research studios such as LMN's Technical Studio and others suggests wider adoption will come sooner rather than later. The conceptual design framework developed for the class offers one possible entry point for wider adoption of computational design within architectural and structural engineering firms that would like to experiment with use of computational design tools and techniques.

It is also advantageous to the engineering profession to have future employees being introduced to not only the way designers of the built environment approach problem solving but also the computational tools and methods used to create the solutions. The engineering students were quick to grasp the power and utility of Rhino/Grasshopper visual scripting. The ability to move analysis such as seismic design out of spreadsheets and into a visual realm of 3D modeling was powerful. Engineering students created algorithms for calculating and visualizing building and assembly-scale characteristics like centers of rigidity. Engineering and architecture students were able to see real time responses to changing parameters to collectively understand the implications of their design decisions.

In professional practice there is always a tension between the needs of practice today and projecting the needs of practice five to ten years into the future. Not all practices have the financial ability to create in-house research studios. By partnering with the Academy, practitioners can help develop the discourse and tools of future practice while also contributing to the preparedness of students for future employment. It is the belief of the authors that one role of the Academy is to project the future state of practice and to develop tools and students that define that future state while also having strong fundamentals for practice today. As a land grant institution, WSU cannot stop at just projecting these future states and preparing students. It must also facilitate the application of new materials, tools, and methods in practice. The Integrated Design Lab is the vehicle designed to accomplish that task.

\section{APPLICATION METHODS: IDL}

To accelerate design and manufacturing market adoption of mass timber systems, the Integrated Design Lab (IDL) compliments the student teaching model of IDX by conducting research and outreach activities with industry and professional practice partners. The State of Washington (and the Seattle metropolitan area in particular) is served by progressive and innovative professional architecture and engineering practitioners competent to engage and apply discovery initiated in academic studio and labs. To facilitate this engagement, the IDL provides technical design assistance and market diffusion activities to professional AECO teams as part of an allied regional network of university labs in Spokane (Washington State University), Seattle (University of Washington), Portland (University of Oregon), Boise (University of Idaho), and Bozeman (Montana State University). The network seeks to transform design, construction, and building operational practices to advance highperformance building designs that are more comfortable for people, require less carbon and energy to construct and maintain, and enhance the health and productivity of inhabitants. Digital modeling, analysis, and fabrication methods tested with faculty and students in IDX are applied to real-world projects. Innovations from the IDX studio are advanced to formal commercialization and tech transfer outlets and inform methods necessary to integrate disparate concerns of stakeholders across entire mass timber supply chains from forest to building site. Market diffusion of mass timber systems in the United States requires holistic 


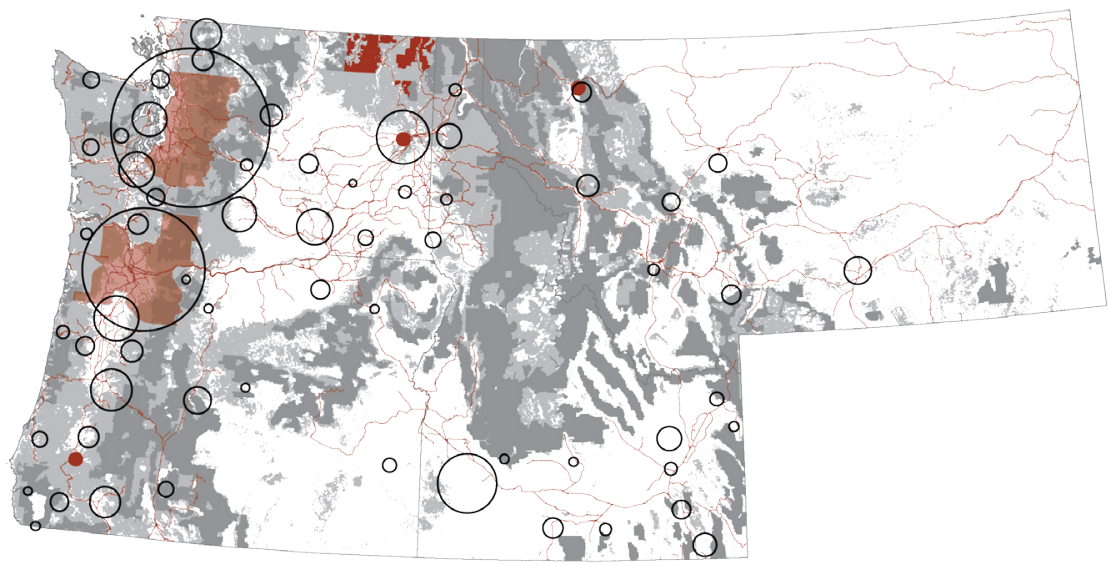

integration of cradle-to-gate manufacturing with the design, engineering, and construction of buildings. To accomplish this, the IDL has developed strategic supply chain partnerships including a lumber producer, an industrial CLT manufacturer, and a digital fabrication and systems integrator to complement existing WSU partnerships with the AECO (architecture, engineering, construction, and operation) community primarily in the metropolitan Seattle and Spokane market areas. Many of the manufacturing and design partners collaborate in the student and teaching faculty activities of IDX. IDX provides an entry point for engagement with academinc design research initiatives which often leads to deeper commitments with sponsored research or competition activities of the IDL. This engagement is critical for universities to gauge relevance of research activities with practice and to gain cost share commitments often necessary to secure grants.

IDL manufacturing efforts are aimed at delineating needs of a key existing gap of prefabrication of mass-customized panel assemblies utilizing digital fabrication and advanced manufacturing technologies. This step in the supply chain moves construction activities into the mills and factories thereby facilitating rapid on-site construction and transfer of value up the supply chain to the lumber and manufacturing sectors. Addressing this gap has additional value of strengthening the role of AECO teams in the manufacturing process. While prefabrication concepts have a deep history in architecture, meaningful realization of prefabricated mass-customized building assemblies has been strengthened with the emergence of digital modeling and manufacturing processes.

In addition to the technically savvy AECO teams, the IDL utilizes digital methods of parametric design and digital manufacturing with traditionally analog partners in mature industries such as lumber milling and lean manufacturing. This broad technomarket integration brings AECO teams closer to realizing Refabricating Architecture (Kieran and Timberlake, 2004) ideals. These wide-ranging concepts from mass timber assembly-scale design to supply chain design were born in the IDX studio environment. The incubation in IDX and focused development in IDL led to successful federal USDA forest product and wood innovation grant proposals that support sponsored research and teaching activities related to technomarket analysis of CLT supply chains and design application. This research considers multiple economic, environmental, and human-centric factors in the design of building typologies across multiple sectors including commercial, housing, and industrial uses. This holistic approach to building design engages architecture and engineering practitioners in the Pacific Northwest seeking a high level of sustainability and performance-based design (Figure 5).

Figure 4: PNW Forest Resources and

Urban Markets 

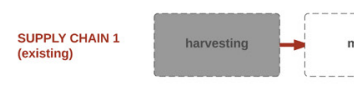

$\underset{\substack{\text { SuppLY CHAIN } 2 \\ \text { (proposed) }}}{2}$
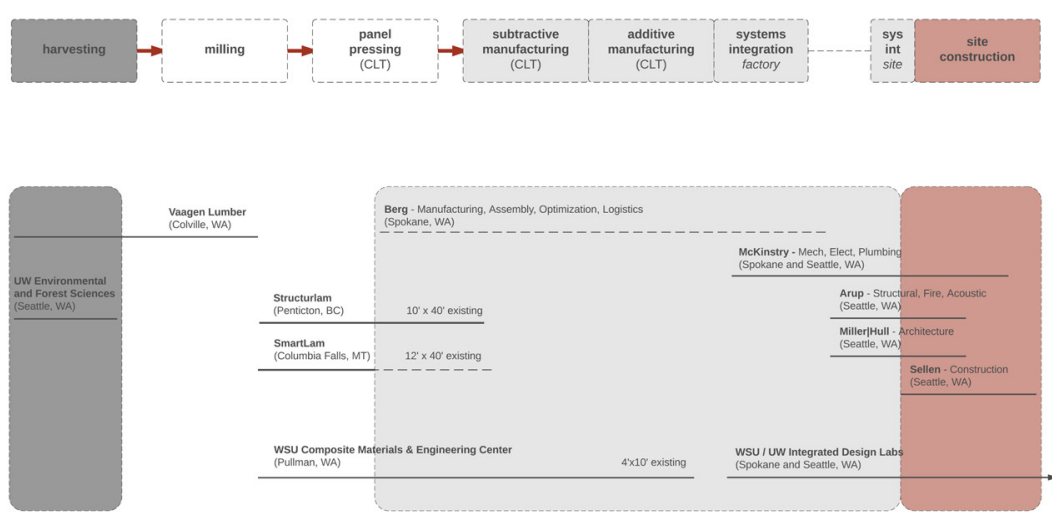

\section{FUTURE}

The structure of IDX and the IDL was created to provide Practice and the Academy the tools, techniques and opportunity to overcome their 'striated spaces' and become deterritorialized nomadic innovators in the words of Delueze and Guatarri. Within IDX, exploration of new tools and the development of new frameworks and methods developed in collaboration with practitioners equip students to be inventive future practitioners prepared to tackle the grand challenges that await them. Complimentary design research activities in the IDL deeply engage partners across the entire wood industry to develop cutting-edge holistic cradle-to-gate systems for utilizing our renewable wood resources in the creation of our built environment.

Future IDX studios will continue to advance emerging concepts at the intersection of practice and the academy to explore multi-scalar aspects of mass timber design utilizing computational design and digital fabrication including: supply chains and life cycle assessment (regional scale), multiple typologies (building scale), high-performance seismic connections tunable for specific performance characteristics (assembly scale), and macro 3D printing methods with wood (material scale).
Figure 5: Mass Timber Supply Chain Scenarios and Partners

\section{ENDNOTES}

Ballantyne, Andrew. Deleuze And Guattari for Architects. London: Routledge, 2007. Print.

Boyer, Ernest L. Scholarship Reconsidered: Priorities of the Professoriate. Princeton, NJ: Carnegie Foundation for the Advancement of Teaching, 1990. Print.

Brown, Valerie A., John A. Harris, and Jacqueline Y. Russell. Tackling Wicked Problems through the Transdisciplinary Imagination. London: Earthscan, 2010. Print.

Buchanan, Richard. "Wicked Problems In Design Thinking." Design Issues 8.2 (1992): 5. Web.

Cross, Nigel. Designerly Ways of Knowing. London: Springer, 2006. Print.

Deleuze, Gilles, and Guattari Félix. A Thousand Plateaus: Capitalism and Schizophrenia. Minneapolis: University of Minnesota Press, 1987. Print.

Kieran, Stephen, and James Timberlake. Refabricating Architecture: How Manufacturing Methodologies Are Poised to Transform Building Construction. New York: McGraw-Hill, 2004. Print.

Michel, Ralf. Design Research Now: Essays and Selected Projects. Basel, Switzerland: Birkhäuser, 2007. Print. 